\title{
Protective strategy of Crowbar circuit when network voltage drop sharply
}

\author{
Xu Shu-Wei ${ }^{1}$ \& Dong Yan ${ }^{1}$ \& Zhang Yi-Yang ${ }^{1}$ \\ Wang Yi-bing ${ }^{2} \&$ Yuan Shou-bin ${ }^{2}$ \\ ${ }^{1}$ Changchun Institute of Technology Department of Electronic Engineering \\ ${ }^{2}$ Changchun University of Technology the school of Electrical and Electronic Engineering 130012
}

KEYWORD: Wind power generation Voltage drop Crowbar

ABSTRACT: When network voltage drop sharply, if rest energy of wind power system can't be absorbed effectively, it will affect system security. This paper presents a new protection scheme of Crowbar circuit. Moreover, the effectiveness of realizing the high voltage ride through of DFIG is validated by simulation.

\section{INTRODUCTION}

When the serious voltage fault of power grid happened, the system can not produce electric energy to the power grid. The wind turbine will keep rotate for a while because of the inertance effect \&. There will be a part of the energy which will be absorbed by the system without no other way, and this will affect the safety of the wind power system. Thus we must increase the hardware circuit under the base of the original wind power system. The Crowbar protective circuit is the most effective method and most commonly used in actual operation, which can absorb the rest energy of the wind power system quickly.

\section{CROWBAR PROTECTIVE PRINCIPLE}

The Crowbar protective circuit will be connected to the wind turbine generator when the serious voltage fault of power grid happened, thus the current will flowed the resistance of the circuit. According to the characteristics of the resistance, resistance belong to the energy dissipating element, the rest of the energy will be consumed in the form of heat. The protective circuit can shorten the time of attenuation of the rotor flux and quicken the process of demagnetization of doubly fed induction generator. Crowbar protective circuit can be divided into two forms, active and passive.

At the beginning of the wind power generation, the effect of syntactic passive Crowbar protectivecircuit is used to protect the wind turbine from damage. Due to the condition of the wind driven generator be changed, the working condition of the protective circuitis same as squirrel-cage induction motor, it will cost lots of reactive power. In2003, The E.ON, German company, brings up new demands for wind power integration, especially in the aspect of protectivecircuit, so the passive Crowbar protective circuit will not be suitable. In order to make wind turbine meet requirements of power operators, the convertor besides the rotor of wind power generation can start work again under the premise of not be off-grid, so the protectivecircuit must be removed at any ment .Therefore the protective circuit composed with SCR and GTO are emerged, such as the Crowbar protective circuit. These power electronic devices have the function of imposed commutation. The circuit can cut off the rotor circuit at any moment, so it can meet requirements of power grid. 


\section{COMPARATION AND OPTIMIZATION FOR THE STRUCTURE OF CROWBAR}

\section{Protective principle of passive move}

At the beginning of the wind power generation, the effect of the circuit is to protect the wind turbines, passive protective circuit is usually be choose, we always call it thyristor protective circuit . Picture 1 shows the two main passive Crower protective circuit.

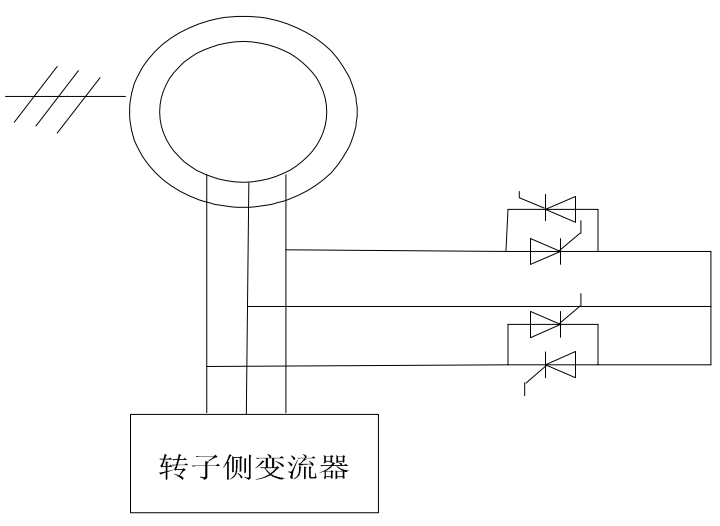

Figure 1(a) . Antiparallel protective circuit

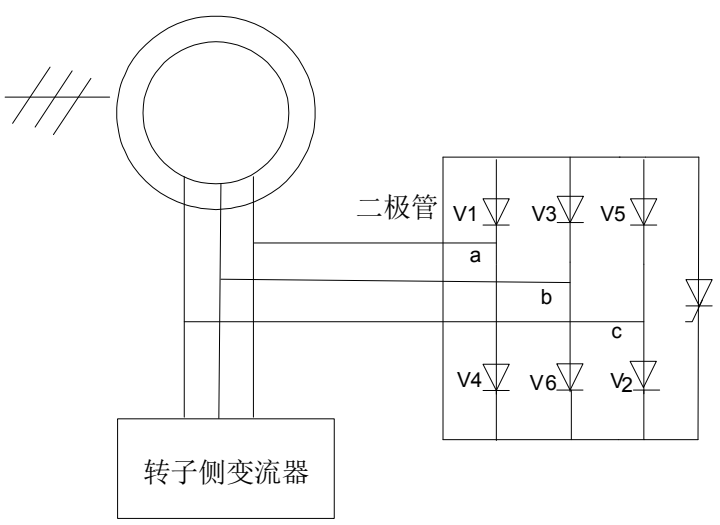

Figure 1(b). Rectifier bridge protective circuit

The circuit in the picture 1 (a) is composed with two AC switches, Two thyristors are antiparallel connected. The thyristor is turned on by triggering signal when grid voltage fault occurs, so that the AC switch will be turned on. The current generated from the rotor circuit will flow the switch instead of converter, so it will protect the converter. DC component will be produced in the rotor circuit when grid voltage fault occurs. It will be difficult to turn off the switch of thyristor. It is difficult to design the absorbing circuit of this circuit is difficult

The circuit in picture1 (b) is different from the circuit in picture1 (a), it is composed with diodebridge rectifier and thyristor which is to protect the circuit. The diode of the circuit is not controlled and the thyristor is half-controlled. The thyristor is turned on by triggering signal when the maximum which is higher than the numerical value that the system can bear is detected, so that the protective circuit is connected with the rotor circuit in DFIG and the large current will flow the protective circuit, the rotor side converter will be short out. We can turn on the thyristor, but we can't turn it off, so that the time that transient current turned to be zero will be longer. In order to solve this problem, we can cascade a resistance in the protective circuit, so that the time will be shorten. Compared with the circuit in picture1(a), this circuit just use a thyristor which should be controlled, but the disadvantage of the circuit is that it is very difficult to turn off the thyristor.

Through the analysis that we can know the passive move circuit can protect the Wind turbines when the fault occurs, but it can't play the role of supporting when power grid voltage breakdown and it 
can't provide electricity to the power grid in the process that the power grid is recovered, so that the circuit can't meet the quest of the power grid, so another circuit shows up, which is the active Crower protective circuit, and is able to cut the rotor circuit at any time and meet the quest of power grid

\section{Introduction and analyze of active leverage protective circuit}

With the rapid development of power electronic technology, New-style of full controlled devices emerged such as IGBT, GTO. The new style of power electronic devices have the function of imposed commutation .It is because of the active Crowbar protectivecircuit composed with these new devices, the controller can send trigger signal to trigger circuit according to the fault current when the serious voltage failure of power grid happened. The controller sent signal to make it turn off when the malfunction is removed. So the wind turbine system can return to the condition before the malfunction and through the process of malfunction without separating with the power grid .Picture 2 shows the structure of some main active Crowbar protective circuit

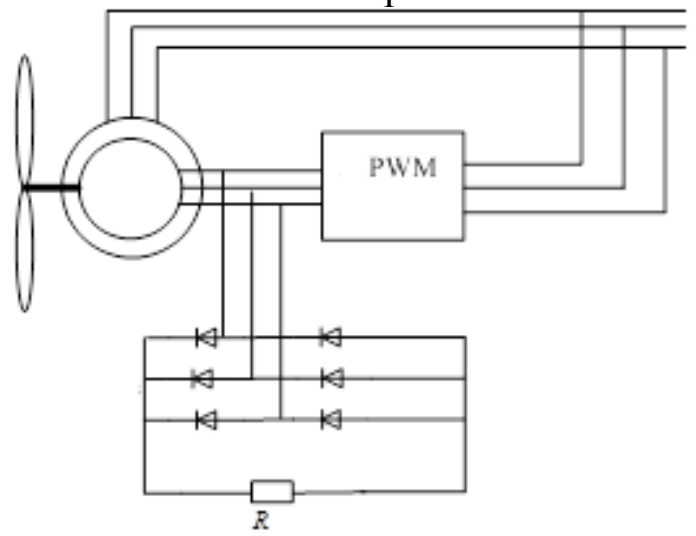

(a)

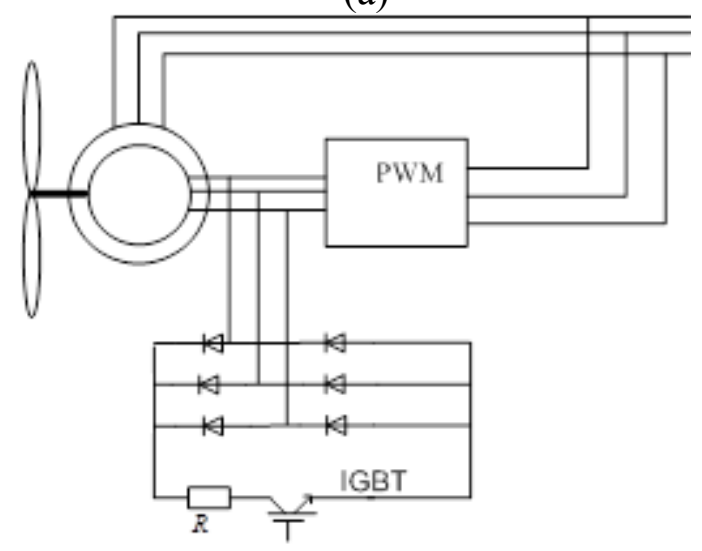

(b)

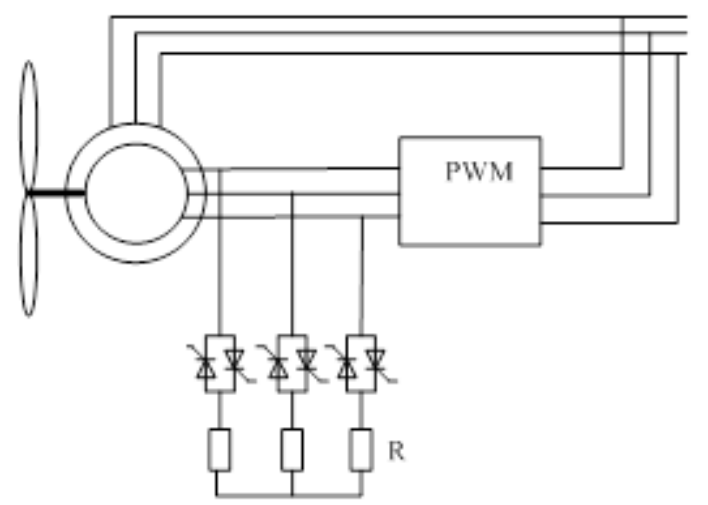

(c) 


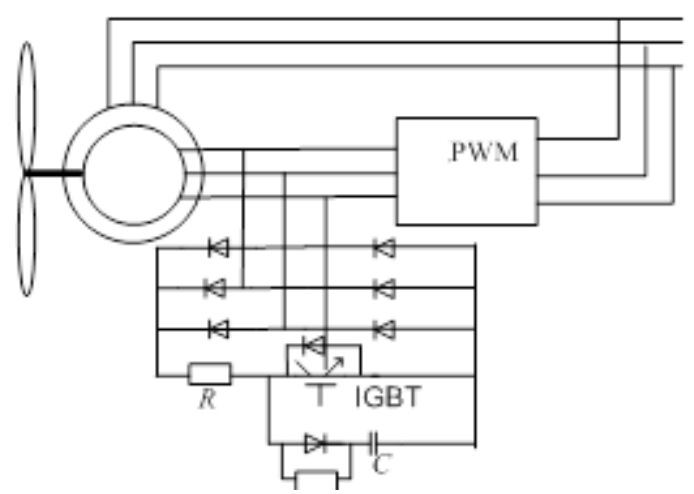

(d)

Figure2. The structure of some main active Crowbar protective circuit

The circuit in figure 2 (a), which is usually called mixed type circuit, is improved from passive protective circuit. Each bridge arm was composed of the cascade of diode and controller. The circuit in figure 2 (b) is the type of IGBT Crowbar protective circuit. This circuit uses the structure that diode rectifier bridge and IGBT devices and resistors are connected in series. Make the circuit and doublyfed induction generator rotor linked, the converter besides rotors will be protected when the serious voltage failure of power grid happened. The Crowbar protection circuit in Figure 2 (c), which is composed of three pairs of anti-parallel can turn off device, connect itself with DFIG's rotor. When fault occurs, the trigger signal make the power electronic devices in the circuit conduct, and then shut down converter to make it stop working, and the overcurrent will flow through the protection circuit to protect the converter at rotor side of the doubly-fed induction generator from being damaged. During the time from failure of the power grid voltage to normal, doubly-fed induction generator is not separate from the power grid. When grid voltage returns to normal level, this circuit can be removed by the power electronic device to make the wind power system run at normal working condition.

Figure 2 (d) show the IGBT bridge with bypass resistance type Crowbar protection circuit, which is composed of a diode rectifier bridge and IGBT as well as resistor. The circuit and the double-fed induction generator rotor are connected together. when there is a fault, the overcurrent will flow through the protection circuit if the single IGBT is turned on by trigger signal. Because it is easy to use IGBT to turn off or open protection circuit several IGBT in parallel are generally used together in practical application, which will reduce the impact from the over current to the system ${ }^{[5]}$.

For these four circuits introduced above, whether the selected resistance can protect the circuit is crucial. If the resistance in the protective circuit is very small, the over current can't decay quickly, and there will be a bad protective effect. If the resistance in the protective circuit is very large, the doubly fed induction generator rotor converter output voltage is too high when the fault occur, which may burn out the power electronic devices. Therefore, the bypass resistance $\mathrm{R}$ need overall consideration $^{[6,7]}$.

\section{A NEW BYPASS PROTECTION CIRCUIT}

Based on the above mentioned hardware protection circuit, a new type of protection circuit[55] is presented. The circuit structure is shown in Figure 3. 

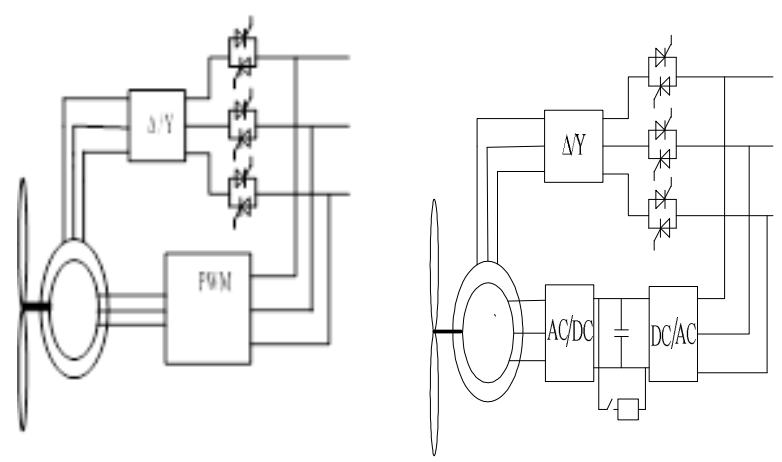

Figure 3. New Crowbar protection circuit

The new circuit shown in Figure 3 (a) is also composed of an antiparallel controllable device, but it is mounted on the stator side of a doubly fed induction generator. When the fault occurs, it will generate very large current, in order to reduce its impact on the system, the rotor side converter of doubly fed induction generator rotor side converter is generally taken by IGBT power electronics devices. Because after the elimination of the fault, the grid voltage from the voltage fault return to the normal voltage last for a brief time, the transient current generated in the stator side of the doubly fed induction generator is very large. Anti parallel power electronic devices of the circuit can rise the stator side voltage which will reduce the transient current generated by the stator ${ }^{[8]}$.

When the wind power generation system is running in normal working condition, the power electronic device will reduce the efficiency of wind power generation system. In order to improve the efficiency of the system, we can use the converter to replace the power electronic devices. However, there are also shortcomings. Whether they are open or closed will spend much time and affect the system's response speed when failure occurs.

When the rotor side of the doubly fed induction generator input the energy of high power to the DC side by the converter, the capacitor voltage is raised. But when the DC side capacitor is elected, it main based on the DC side of the pressure rating.

So we can use figure 3 (b) of the circuit structure, when after the occurrence of a fault, large capacity capacitor at the DC side of doubly fed induction generator converter can be replaced by a crowbar protection circuit due to the action of crowbar protection resistor, DC side voltage can be well controlled.

The use of active crowbar protection circuit can meet the requirements for the operation of the wind power generation, but in the actual operation of using what kind of active crowbar protection circuit, we need to adopt the most suitable circuit according to the actual situation. This paper will focus on the research of active Crowbar protection circuit, as shown in Figure 3 (b).

\section{SIMULATION AND ANALYSIS OF THE CROWBAR CIRCUIT OF THE ROTOR SIDE}

In order to verify the validity of the proposed Crowbar control strategy, based on the DFIG system model above, a 1.5 MW doubly fed induction generator is simulated. The running speed of the generator is $1620 \mathrm{r} / \mathrm{s}$; during the time of $200 \mathrm{~ms}$, the voltage of the power network collapsed from 1 (PU) to 0.2 (PU).In accordance with the motor practice, regulate that $\mathrm{P}<0 、 \mathrm{Q}<0$, which respectively represent generator output active power and reactive power. Using the Crowbar protection circuit structure as is shown in Figure 4 (b) to simulate, simulation results are as follows: 


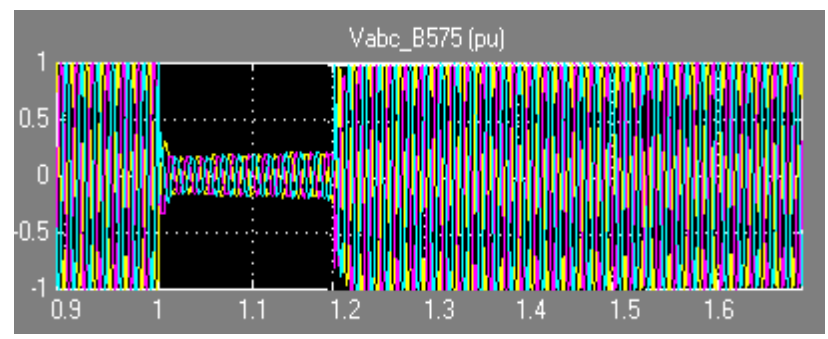

Figure 4(a) .Stator voltage of DFIG

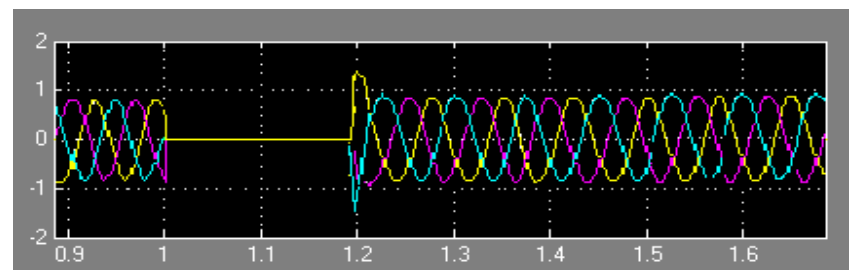

Figure 4(b). Current of rotor-side converter

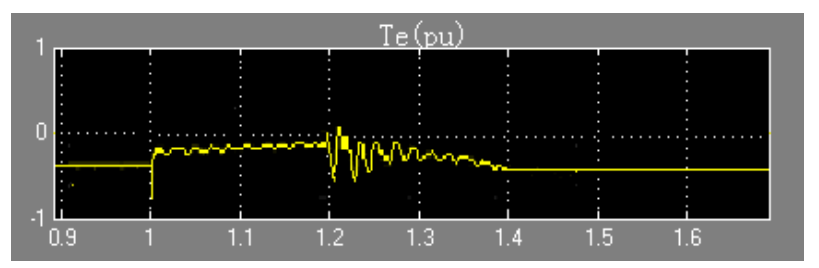

Figure 4(c). Electromagnetic torque of DFIG

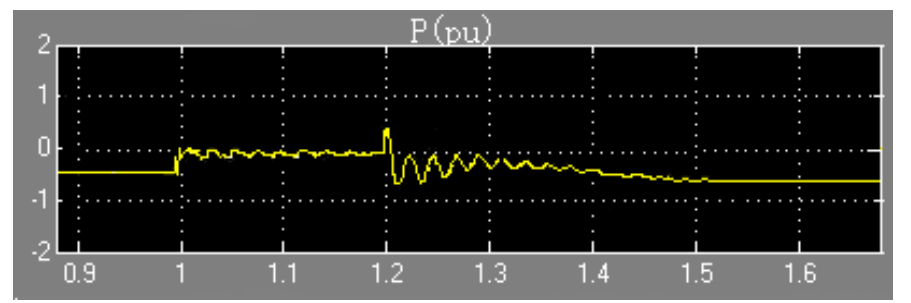

Figure 4(d). Output active power of DFIG

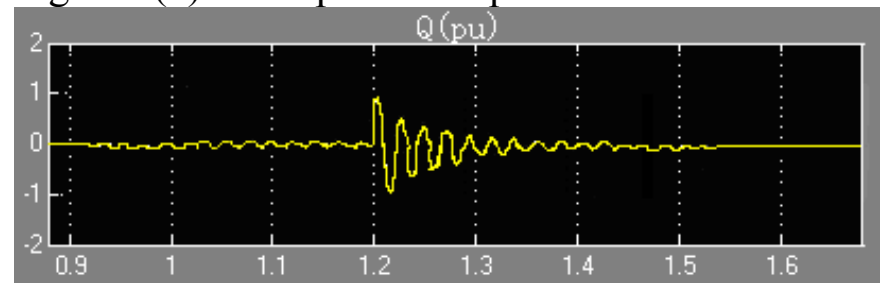

Figure 4(e). Output reactive power of DFIG

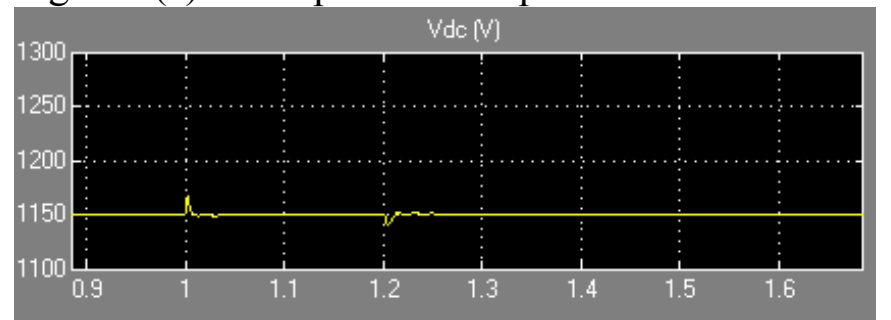

Figure 4(f). DC-link voltage

Figure 4 shows the simulation results of the power system of Crowbar when the power grid voltage sags to $0.2 \mathrm{pu}$.

As can be seen from Figure 4, when the power grid voltage falls, the stator of the generator is connected directly to the grid. Stator voltage will be mutated, according to the principle of flux conser- 
vation, the stator flux of generator will remain constant at the instant of failure. So the DC component which gradually decays over time will appear in the stator winging, and the speed of its decay depends on the stator winding parameters of the doubly fed induction generator. During the period of the grid voltage recovery, the stator winding of the double fed induction generator will undergo a similar process, so in the period of grid voltage sag and voltage recovery, the stator winding will have a larger current. Due to the coupling from the doubly fed induction generator's stator winding flux and rotor winding flux, the rotor winding will overcurrent caused by stator flux DC component which keep stationary in space because of the rotor's high speed cutting. In the use of Crowbar protection circuit, the rotor winding will be shorted by the Crowbar protection circuit due to the overcurrent, and the rotor current form into a circuit through the bypass protection resistance. Serious into the bypass protection resistance is equivalent to increasing the impedance of the rotor, which can effectively reduce the maximum current of the rotor circuit in the voltage sag and recovery process.

\section{REFERENCE}

[1] LI Jian-lin , ZHAO Dong-li, XU Hong-hua. Analyze of crowbar circuit for variable speed constant frequency doubly fed induction generator[J]. Renewable Energy, 2006(129):57-59.

[2] JIANG Xue-dong, ZHAO Fang. Crowbar Control Strategy for Doubly Fed InductionGenerator of Wind Farm During Power Grid Voltage Dips[J]. Power System Technology, 2008,32(12):8489.

[3] ZHANG Xue-guang; XU Dian-guo. Research on control of DFIG with active crowbar under symmetry voltage fault condition[J]. Machines and Control,2009, 13(01):99-103.

[4] LI Jian-lin. Low voltage operation technology of wind power generation system [M]. Beijing: Mechanical industry publishing house, 2008.

[5] MORREN J, DE HAAN S W H. Ride through of wind turbines with doubly-fed induction generator during a voltage dip[J].IEEE Transactions on ergy Conversion- 2005 20(2): 435-441.

[6] Gomis-Bellmunt O, Junyent-Ferre A., Sumper A., Bergas-Jan J. Ride-through controlof a doubly fed induction generator under unbalanced voltage sags [J]. EnergyConversion, IEEE Transactions on, 2008, 23(4):1036-1045.

[7] JNHRANEN. Voltage ride through of a doubly-fed generator equipped with an active Crowbar [M].EPE-PEMC RigaLatvia. 2004.

[8] A.Petersson,S.Lundberg, and T.Thiringer. A DFIG wind-turbine ride-throughsystem on the energy production[C], in Proc. of Nordic Wind Power Conference, Chalmers of Technolgy, Sweden.2006,5:1-7. 